\title{
SUSCETIBILIDADE DA LAGARTA-DO-CARTUCHO AO SEU VÍRUS DE POLIEDROSE NUCLEAR, EM DISTINTOS ESTÁDIOS LARVAIS ${ }^{1}$
}

\section{Sérgio Arce Gomez ${ }^{2}$ \\ Flávio Moscardi ${ }^{3}$ \\ Daniel Ricardo Sosa-Gómez ${ }^{3}$}

\section{RESUMO}

O objetivo deste trabalho foi verificar a suscetibilidade da lagarta-do-cartucho, Spodoptera frugiperda (Smith, 1797), em diferentes estádios larvais, a um isolado geográfico de seu vírus de poliedrose nuclear (VPN), em seis bioensaios. Larvas do I ao VI ínstares foram alimentadas com dieta artificial contendo diversas concentrações do virus; em corpos poliédricos de inclusão (CPI) por mL de dieta artificial. A análise estatística (Probites) evidenciou, pela ausência de sobreposição das amplitudes dos intervalos de confiança das concentrações letais médias, que: larvas dos dois primeiros ínstares não diferem em suscetibilidade; as de segundo são cerca de 3 e dezessete vezes mais suscetíveis que as de terceiro e quarto ínstar, respectivamente; as de terceiro são, aproximadamente, 6 vezes mais suscetíveis que as de quarto; e as de quinto e sexto ínstares têm baixa suscetibilidade, mesmo a altas doses como as de $1.024 .000 \mathrm{e}$ 2.048.000 CPI por $\mathrm{mL}$, respectivamente .

Palavras-chave: lagarta-do-cartucho, Lepidoptera, Noctuidae, isolado geográfico, VPN, virulência, bioensaios.

${ }^{1}$ Extraído da Tese de Doutorado apresentada pelo primeiro autor a Universidade Federal do Paraná.

${ }^{2}$ Embrapa Agropecuária Oeste, Caixa Postal 661, CEP 79804-970, Dourados, MS. Email: sergio@cpao.embrapa.br

${ }^{3}$ Embrapa Soja, Caixa Postal 231, CEP 86001-970, Londrina, PR. E-mail: moscardi@cnpso.embrapa.br 


\section{ABSTRACT}

\section{SUSCEPTIBILITY OF Spodoptera frugiperda (SMITH) AT DIFFERENTS LARVAL STAGES TO ITS NUCLEAR POLYHEDROSIS VIRUS.}

This work aimed to verify the susceptibility of the fall armyworm, Spodoptera frugiperda (Smith), at different larval stages, to a geographical isolate of its nuclear polyhedrosis virus (NPV), using seven bioassays. Larvae from I to VI stages were fed on an artificial diet containing different virus concentrations, in polyhedral inclusion bodies, per $\mathrm{mL}$ of diet. The Probites analysis showed, based on the non-overlaping of the confidence intervals of the lethal average concentrations, that the two first instars are equal in susceptibility; the second instar larvae are about three and seventeen times more sensitive than, respectivily, the third and the fourth instars; the third instar larvae are about six times more susceptible than those of fourth instar. The fifth and the sixth instars showed low suscetibility to doses as high as $1,024 \times 10^{3}$ and $2,048 \times 10^{3}$ PIB per $\mathrm{mL}$, respectivly.

Key words: fall armyworm, Lepidoptera, Noctuidae, geographic isolates, NPV, PIB, virulence, bioassays.

\section{INTRODUÇÃO}

De acordo com Sparks (1979) a lagarta-do-cartucho, Spodoptera frugiperda (Smith, 1797), pode alimentar-se de várias espécies vegetais, mas os seus hospedeiros preferenciais são o milho (Zea mays L.), amendoim (Arachis hypogaea L.); sorgo (Sorghum bicolor L.) e o capim-bermudas (Cynodon dactylon L.). Na ausência dessas espécies, pode atacar a cultura da soja (Glycine max (L.) Merril) (Lunginbill, 1928).

Estima-se que a perda média anual causada pelo inseto, nos Estados Unidos da América do Norte, seja da ordem de 300 milhões de dóla- 
res, sendo que entre os anos de 1975 e 1977, provavelmente, foi superior a 500 milhões de dólares (Mitchell, 1979). No Brasil, a S. frugiperda ataca amendoim, algodão (Gossypium hirsutum L.) e diversas espécies de gramíneas cultivadas (Nakano et al., 1981), inclusive o trigo (Triticum aestivum L.) em que é considerada a principal desfolhadora nas lavouras situadas ao norte da latitude $24^{\circ} \mathrm{S}$ (Embrapa, 1999). Ainda no Brasil, Carvalho (1970) citou que esta praga é capaz de causar prejuízo de até $34 \%$ na cultura do milho e, conforme Moscardi \& Kastelic (1985), pode também atacar a cultura da soja.

Entre os agentes de controle biológico natural da lagarta-do-cartucho-do- milho, freqüentemente é referida a ocorrência de um vírus de poliedrose nuclear (VPN) em considerável parte da área de distribuição geográfica do inseto (Kuno, 1979; Agudelo et al., 1983; Moscardi \& Kastelic, 1985; Fuxa, 1987; Richter et al., 1987; Shapiro et al., 1991; Valicente \& Cruz, 1991).

Diversos autores verificaram que a magnitude da virulência de determinada dose de VPN é inversamente proporcional à idade da larva do lepidóptero hospedeiro. Assim, Morris (1962) constatou que o percentual de mortalidade de Lambdina fiscellaria somniaria (Hulst), sob efeito de seu VPN, incrementou na razão inversa do avanço da idade das larvas. Outrossim, Stairs (1965) constatou que um VPN de Malacosoma disstria (Hübner) foi 343 vezes mais virulento a larvas de primeiro ínstar que para as de terceiro. Já Ignoffo (1966) registrou mortalidade $88 \%$ mais elevada em larvas neonatas de Heliothis zea (Boddie) que nas de seis dias de idade, quando submetidas a uma dose de VPN de Heliothis spp. De maneira análoga, Doane (1967) evidenciou que uma dose de VPN de Porthetria dispar (Linnaeus) foi 10,8 vezes mais virulenta a larvas de primeiro ínstar que a de terceiro. Do mesmo modo, Williams \& Payne (1984) verificaram que um VPN de H. zea foi cerca de 100 vezes mais virulento a larvas recémeclodidas que para as de quinto ínstar e Moscardi (1983) constatou que o VPN de Anticarsia gemmatalis Hübner foi aproximadamente 39 vezes mais virulento a larvas de segundo ínstar de seu hospedeiro natural que para as de quinto e Gomez et al.(1999) registraram que, 
dentre sete isolados geográficos testados, o oriundo de Sertaneja, PR, foi o mais virulento a larvas de segundo ínstar de $S$. frugiperda.

$\mathrm{O}$ objetivo deste trabalho foi verificar as diferenças de suscetibilidade, entre ínstares larvais da lagarta-do-cartucho, a um isolado geográfico de seu VPN, de Sertaneja, PR.

\section{MATERIAL E MÉTODOS}

A colônia de $S$. frugiperda foi cedida pelo laboratório de Entomologia do Centro Nacional de Pesquisa de Milho e Sorgo (CNPMS), da Embrapa, Sete Lagoas, MG. A criação foi realizada no Laboratório de Entomologia do Centro Nacional de Pesquisa de Soja (CNPSo), em Londrina, PR, seguindo-se o método de Hoffman-Campo et al. (1985) para A. gemmatalis.

O isolado de VPN de S. frugiperda, procedente de Sertaneja, PR (Moscardi \& Kastelic (1985) foi multiplicado em larvas de terceiro ínstar de $S$. frugiperda, induzidas a alimentar-se em dieta artificial (Greene $e t$ al., 1976), impregnada com suspensões aquosas do patógeno. Os insetos mortos pelo vírus foram macerados com água destilada e coados através de uma camada de algodão. A suspensão foi transferida para tubos de polipropileno $(50 \mathrm{~mL})$, que foram submetidos a centrifugação (centrÍfuga Sorval RC-5b; rotor SS-34) de $5.000 \mathrm{rpm}$, por quinze minutos. $\mathrm{O}$ precipitado resultante foi homogeneizado em água destilada estéril.

Em seguida, elaborou-se uma suspensão inicial do vírus, com 20 $\mathrm{mL}$ de suspensão concentrada do patógeno. Posteriormente, do líquido, homogeneizado em Erlenmeyer, foi retirada, com pipeta do tipo Pasteur, uma alíquota, logo transferida para uma câmara de Neubauer. Os corpos poliédricos de inclusão (CPI) foram, então, contados, sob microscópio composto, com aumento de 400 vezes, para determinar sua concentração na suspensão, com quatro repetições.

Os estádios (I ao VI) de $S$. frugiperda e as respectivas concentrações virais com que as larvas foram tratadas encontram-se na Tabela 1. 
Tabela 1. Doses de vírus de poliedrose nuclear (VPN), em corpos poliédricos de inclusão (CPI), ministradas, em seis bioensaios, a Spodoptera frugiperda de diferentes ínstares larvais ${ }^{1}$.

\begin{tabular}{cccccccc}
\hline \multirow{7}{*}{ Instar } & \multicolumn{7}{c}{ Doses de VPN } \\
\cline { 2 - 8 } & 1,00 & 2,50 & 6,25 & 15,60 & 39,06 & 97,65 & - \\
\hline I & $1,0310^{3} / \mathrm{mL}$ de dieta artificial) \\
II & 1,00 & 2,50 & 6,25 & 15,60 & 39,06 & 97,65 & 244,1 \\
III & 2,50 & 6,25 & 15,60 & 39,06 & 97,65 & 244,10 & - \\
IV & 6,25 & 15,60 & 39,06 & 97,65 & 244,10 & 610,00 & - \\
V & 32,00 & 64,00 & 128,00 & 256,00 & 1024,00 & - & - \\
VI & 64,00 & 128,00 & 256,00 & 512,00 & 1024,00 & 2048,00 & - \\
\hline
\end{tabular}

${ }^{1} \mathrm{O}$ tratamento testemunha recebeu dieta isenta de vírus.

A cada $540 \mathrm{~mL}$ de dieta acrescentaram-se $60 \mathrm{~mL}$ de suspensão viral, previamente diluída para possibilitar a obtenção de cada uma das concentrações desejadas. Na seqüência, o produto foi homogeneizado com o auxílio de uma batedeira de bolo comum. Para a testemunha, foram utilizadas $540 \mathrm{~mL}$ de dieta, acrescida de $60 \mathrm{~mL}$ de água esterilizada. $\mathrm{O}$ volume de $600 \mathrm{~mL}$ de dieta contaminada, ou não (testemunha), foi transferido para o interior de 60 copos de plástico $(50 \mathrm{~mL})$, de forma que cada um contivesse em torno de $10 \mathrm{~mL}$. Após o esfriamento da dieta, colocou-se, com o auxílio de pincel, uma larva de cada ínstar em cada um dos 60 recipientes, exceto quanto às de sexto ínstar; destas foram utilizadas apenas 54 indivíduos. Após tal procedimento, os recipientes foram fechados com tampas de cartolina e transportados para o interior de câmaras climatizadas (temperatura: $26^{\circ} \pm 2^{\circ} \mathrm{C}$; umidade relativa: $60 \pm 10 \%$; fotoperíodo: 14 horas). Do quinto dia em diante, as larvas foram observadas, diariamente, até a fase de prépupa, para registro de mortalidade e/ ou fornecimento adicional de dieta.

As análises foram realizadas sobre o somatório do número de insetos mortos pelo vírus, até o décimo quarto dia após a infeção, ou até a 
fase de prépupa. Os cálculos para correção dos dados (Abbott, 1925), das concentrações letais médias $\left(\mathrm{CL}_{50}\right)$, dos intervalos de confiança destas e dos valores dos ângulos de inclinação das retas foram realizados através de um programa de Probites para microcomputadores (Micro Probit 3,0, T.C. Sparks \& Sparks, Lily Research Laboratories, Greenfield, Indiana, EUA).

\section{RESULTADOS E DISCUSSÃO}

Em relação às larvas dos quatro primeiros ínstares, constatou-se que os valores dos ângulos de inclinação das retas dos Probites (b) em relação ao eixo das abcissas, são tipicamente baixos (Tabela 2 e Figura 1), indicando, de acordo com Burges \& Thomson (1971), a tendência a variabilidade a que estão sujeitos ensaios dessa natureza, fato que também pode ser verificado analisando-se as amplitudes dos intervalos de confiança das concentrações letais médias $\left(\mathrm{CL}_{50}\right)$, da Tabela 2 .

Tabela 2. Parâmetros de bioensaios com larvas dos quatro primeiros estádios de Spodoptera frugiperda, alimentadas com dieta impregnada com vírus de poliedrose nuclear.

\begin{tabular}{rcccc}
\hline Instar & $\mathrm{CL}_{50}{ }^{\prime}$ & $\mathrm{IC}^{2}$ & $\mathrm{~b}^{3}$ & $\left(\chi^{2}\right)^{4}$ \\
I & 9.727 & $7.808-12.312$ & 1,30 & $5,78 \mathrm{~ns}$ \\
II & 8.380 & $6.482-10.616$ & 1,05 & $8,41 \mathrm{~ns}$ \\
III & 24.687 & $20.686-29.638$ & 1,70 & $5,46 \mathrm{~ns}$ \\
IV & 142.520 & $104.747-210.102$ & 1,06 & $0,27 \mathrm{~ns}$ \\
\hline
\end{tabular}

${ }^{\prime} \mathrm{CL}_{50}$ : Concentração letal média.

${ }^{2} \mathrm{IC}$ : Intervalo de confiança da concentração letal média.

${ }^{3}$ b: Inclinação das retas dos probites.

${ }^{4} \mathrm{c}^{2}$ : Qui-quadrado.

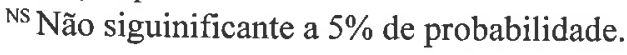




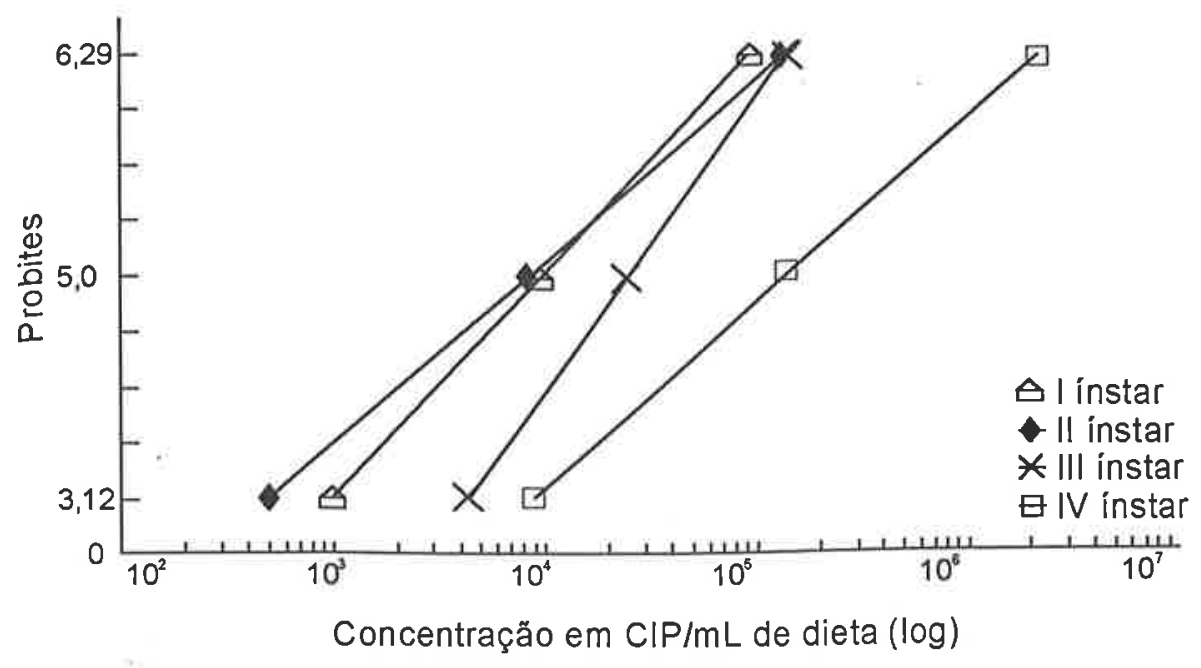

Figura 1. Regressão entre a concentração de corpos poliédricos de inclusão por $\mathrm{mL}$ de dieta $(\log )$ e as probabilidades de mortalidade (Probites) de larvas dos quatro primeiros ínstares de Spodoptera frugiperda.

Com base na ausência de sobreposição entre os respectivos intervalos de confiança das concentraçôes letais médias $\left(\mathrm{CL}_{50}\right)$, constatou-se que entre larvas de primeiro e segundo ínstares de $S$. frugiperda não há diferença de suscetibilidade ao seu VPN, isolado de Sertaneja, PR, mas que as de segundo ínstar são aproximadamente três e dezessete vezes mais suscetíveis que as de terceiro e quarto ínstares, respectivamente; verificou-se ainda que larvas de terceiro ínstar são cerca de seis vezes mais suscetíveis que as de quarto (Tabela 2 e Figura 1). Com base no percentual de mortalidade, as de quinto e sexto ínstares são pouco suscetíveis, mesmo quando as doses foram pronunciadamente mais elevadas (Tabela 3).

O fato de a suscetibilidade das larvas de $S$. frugiperda a seu VPN diminuir na medida em que a idade das mesmas aumenta - exceto quanto às larvas de primeiro e segundo ínstares, que são de igual suscetibilidade 
Tabela 3. Parâmetros de bioensaios com larvas de quinto e sexto ínstares de Spodoptera frugiperda, tratadas com vírus de poliedrose nuclear, em corpos poliédricos de inclusão por $\mathrm{mL}$ de dieta .

\begin{tabular}{|c|c|c|c|c|}
\hline \multirow{2}{*}{ Dose } & \multicolumn{2}{|c|}{ Larvas de V instar } & \multicolumn{2}{|c|}{ Larvas de VI instar } \\
\hline & Número & $\%$ & Número & $\%^{\prime}$ \\
\hline $0^{2}$ & 93 & 1 & 49 & 0 \\
\hline 32000 & 93 & 3 & - & - \\
\hline 64000 & 98 & 1 & 46 & 2 \\
\hline 128000 & 95 & 6 & 41 & 5 \\
\hline 256000 & 95 & 1 & 46 & 4 \\
\hline 512000 & 91 & 9 & 49 & 6 \\
\hline 1024000 & 98 & 10 & 50 & 8 \\
\hline 2048000 & 一 & - & 50 & 8 \\
\hline
\end{tabular}

'Porcentual de larvas mortas pelo vírus, calculado pela fórmula de Abbot.

${ }^{2}$ Testemunha isenta de vírus.

- guarda marcante semelhança com os resultados obtidos por pesquisadores que estudaram a interação de outras espécies de lepidópteros com seus respectivos VPN (Morris, 1962; Stairs, 1965; Ignoffo, 1966; Doane, 1967; Moscardi, 1983; Williams \& Payne, 1984). Estes resultados confirmam que trabalhos de campo visando o controle da $S$. frugiperda com seu VPN devem ser implementados, preferencialmente, quando as larvas estiverem nos dois primeiros ínstares porque, além da baixa capacidade de consumo de alimento (Sparks, 1979), neste período elas são mais suscetíveis ao patógeno, como já fora constatado por Valicente \& Cruz (1991).

Por outro lado, o fato de os indivíduos de primeiro e segundo ínstares terem evidenciado suscetibilidades estatisticamente iguais contribuiu para que não fosse configurada uma identidade irrestrita entre estes resultados e o de outros pesquisadores, que não constataram a mesma igualdade entre os mesmos ínstares larvais de outras espécies de insetos submetidas à ação de seus respectivos VPN (Ignoffo, 1966; Doane, 1967; Magnoler, 1975; Boucias \& Nordin, 1977; Boucias et al.,1980; Moscardi, 1983). A explicação para a igualdade de suscetibilidade entre 
indivíduos dos dois primeiros ínstares de $S$. frugiperda provavelmente resida no fato de que os de primeiro ínstar consomem menos de $0,1 \%$ do total de alimento que necessitam para completar a fase larval (Sparks, 1979). Com isso, é possível que a quantidade de poliedros ingeridos durante o primeiro ínstar não tenha sido suficiente para desencadear uma infecção letal, mas que pode tê-lo sido para ativar o sistema imunológico do inseto. Esta possibilidade, aliada ao aumento da massa corporal (Daoust, 1974), poderia tê-los tornado menos suscetíveis quando atingiram o segundo ínstar. Neste estágio, a quantidade necessária do vírus (referida anteriormente) provavelmente tenha sido atingida, porém numa condição em que a larva já estaria menos suscetível à infecção. Mesmo não sendo comuns relatos de tal natureza na literatura, Smith et al. (1956) observaram que larvas de terceiro ínstar do lepidoptero Harrissima brillians $\mathrm{B}$. \& McD. foram mais suscetíveis a um vírus de granulose que as de primeiro. Contudo faz-se necessário ressalvar que o método utilizado no referido trabalho não foi adequado.

As larvas de quinto e sexto ínstares de $S$. frugiperda foram pouco suscetíveis ao VPN, visto que a concentração de $1.024 .000 \mathrm{CPI} \mathrm{mL}^{-1}$ de dieta causou mortalidade em apenas 10 e $8 \%$ das mesmas, respectivamente; as de sexto ínstar, quando submetidas a uma dose ainda maior (2.048.000 $\mathrm{CPI} \mathrm{mL}^{-1}$ de dieta) não sofreram mortalidade superior a $8 \%$ (Tabela 3), o que confirma a baixa suscetibilidade das larvas dos últimos dois ínstares, mesmo sob tratamento das concentrações mais elevadas de CPI, conforme verificado por Bucher \& Turnock (1983) em relação a Mamestra configurata Walker.

\section{CONCLUSÕES}

1. Não há diferença de suscetibilidade entre larvas de primeiro e segundo ínstares de S. frugiperda, ao seu VPN, isolado de Sertaneja, PR.

2. A partir do segundo ínstar, a suscetibilidade das larvas de S. frugiperda diminui à medida em que a idade delas aumenta.

3. Larvas de quinto e sexto ínstares apresentam baixa suscetibilidade ao seu VPN. 


\section{REFERÊNCIAS BIBLIOGRÁFICAS}

ABBOTT, W. S. 1925. A Method of Computing the Effectiveness of an Insecticide. J. Econ. Entomol., Lanham, 18:265-267.

AGUDELO, F.; M. ROMANO; H. WASSINK,; R. CUELLO DE UZCATEGUI, 1983. Una Polihedrosis de Spodoptera froiperda en Venezuela. Turrialba, São José, 33(3):219-222.

BOUCIAS, D.G.; D.W. JOHNSON; G.E. ALLEN, 1980. Effects of Host Age, Virus Dosage, and Temperature on the Infectivity of a Nucleopolyhedrosis Virus Against Velvetbean Caterpillar, Anticarsia gemmatalis, Larvae. Environ. Entomol., Lanham, 9(1):59-61. BOUCIAS, D.G.; G.L. NORDIN, 1977. Interinstar susceptibility of the

Fall Webworm, Hyphantria cunea to its Nucleopolyhedrosis and Granulosis Viruses. J. Invertebr. Pathol., New York, 30: 68-75. BUCHER, D.G.; W.J. TURNOCK, 1983. Dosage Response of the Larval Instars of the Bertha Armyworm, Mamestra configurata (Lepidoptera: Noctuidae), to a Native Nuclear Polyhedrosis. Can. Entomol., Ottawa, 15:341-349.

BURGES, H.D.; E.M. THOMSON, 1971. Standardization and Assay of Microbial Insecticides. In: BURGES, H.D.; HUSSEY, N.W., ed. Microbial Control of Insects and Mites. London: Academic. p.591-622.

CARVALHO, R.P.L. 1970. Danos, Flutuação da População, Controle e Comportamento de Spodoptera frugiperda (J.E. Smith, 1797) e Suscetibilidade de Diferentes Genótipos de Milho, em Condições de Campo. Piracicaba: ESALQ. 170p. Tese de Doutorado. DAOUST, R.A. 1974. Weight-Related Susceptibility of Larvae of Heliothis armigera to a Crude Nuclear-Polyhedrosis Virus Preparation. J. Invertebr. Pathol., New York, 23:400-401.

DOANE, C.C. 1967. Bioassay of Nuclear-Polyhedrosis Virus Against Larval Instars of the Gypsy Moth. J. Invertebr. Pathol., New York, 9:376- 386. FUXA, J.R. 1987. Spodoptera frugiperda Susceptibility to Nuclear Polyhedrosis Virus Isolates With Reference to Insect Migration. Environ. Entomol., Lanham, 16(1): 218-223. GOMEZ, S.A.; F. MOSCARDI; D.R. SOSA-GOMEZ, 1999. Suscetibilidade 
de Spodoptera frugiperda a Isolados Geográficos de um Vírus de Poliedrose Nuclear. Pesq. Agropec. Bras., Brasília, 34(9):1539-1544. GREENE, G.L.; N.C. LEPPLA; W.A. DICKERSON, 1976. Velvetbean Caterpillar: a Rearing Procedure and Artificial Medium. J. Econ. Entomol., Lanham, 69(4):487-488.

HOFFMAN-CAMPO, C.B.; E.B. de OLIVEIRA; F. MOSCARDI, 1985. Criação Massal da Lagarta da Soja (Anticarsia gemmatalis). Londrina: EMBRAPA-CNPSo. 22p. (EMBRAPA-CNPSo. Documentos, 10).

IGNOFFO, C.M. 1966. Effects of Age on Mortality of Heliothis zea and Heliothis virescens Larvae Exposed to a Nuclear-Polyhedrosis Virus. J. Invertebr. Pathol., New York, 8(2):279-282.

KUNO, G. 1979. A Nuclear-Polyhedrosis Virus of Spodopterafrugiperda Isolated in Puerto Rico. J. Agric. Univ. P. R., Rio Piedras, 63(2):162-169.

LUNGINBILL, P. 1928. The Fall Armyworm. Washington: USDA. 92p. (USDA. Technical Bulletin, 34).

MAGNOLER, A. 1975. Bioassay of Nucleopolyhedrosis Virus Against Larval Instars of Malacosoma neustria. J. Invertebr. Pathol., New York, 25:343-348.

MITCHELL, E.R. 1979. Preface to Fall Armyworm Symposium. Fla. Entomol., Gainesville, 62:81.

MORRIS, O.N. 1961. Quantitative Infectivity Studies on the Nuclear Polyhedrosis of the Western Oak Looper, Lambdina fiscellaria somniaria (Hulst). J. Insect Pathol., 4:207-215.

MOSCARDI, F. 1983. Utilização de Baculovirus anticarsia Para o Controle da Lagarta da Soja, Anticarsia gemmatalis. Londrina: EMBRAPACNPSo. 13p. (EMBRAPA-CNPSo. Comunicado Técnico, 23).

MOSCARDI, F.; J.G. KASTELIC, 1985. Ocorrência de Vírus de Poliedrose Nuclear e Vírus de Granulose em Populações de Spodoptera frugiperda Atacando Soja na Região de Sertaneja, PR. In: EMBRAPA. Centro Nacional de Pesquisa de Soja (Londrina, PR). Resultados de Pesquisa de Soja, 1984/85. Londrina. p.128. (EMBRAPA-CNPSo. Documentos, 15).

NAKANO, O.; S. SILVEIRA NETO; R.A. ZUCHI, 1981. Entomologia 
Econômica. São Paulo: Monsanto. 314p. REUNIÃO DA COMISSÃO CENTRO-SUL-BRASILEIRA DE PESQUISA DE TRIGO, 11., 1995, Cascavel, PR. 1995. Recomendações da Comissão Centro-Sul Brasileira de Pesquisa de Trigo para 1995. Cascavel: OCEPAR. 93p.

REUNIÃO DA COMISSÃO CENTRO-SUL BRASILEIRA DE PESQUISA DE TRIGO, 15., 1999, Dourados, MS. 1999. Recomendações da Comissão Centro-Sul Brasileira de Pesquisa de Trigo para 1999. Dourados: Embrapa Agropecuária Oeste. 128p. (Embrapa Agropecuária Oeste. Documentos, 1).

RICHTER, A.R.; J.R. FUXA; M. ABDEL-FATTAH, 1987. Effect of Host Plant on the Susceptibility of Spodoptera frugiperda (Lepidoptera: Noctuidae) to a Nuclear Polyhedrosis Virus. Environ. Entomol., Lanham, 16(4):1004-1006.

SHAPIRO, D.I.; J.R. FUXA; H.D. BRAYMER; D.P. PASHLEY, 1991. DNA Restriction Polymorphism in Wild Isolates of Spodoptera frugiperda Nuclear Polyhedrosis Virus. J. Invertebr. Pathol., New York, 58:96-105.

SMITH, O.J.; K.M. HUGHES; P.H. DUNN; I.M. HALL, 1956. A Granulosis Virus Disease of the Western Grape Leaf Skeletonizer and its Transmission. Can. Entomol., Ottawa, 88:507-515. SPARKS, A.N., 1979. A Review of the Biology of the Fall Armyworm. Fla. Entomol., Gainesville, 62(2):82-87.

STAIRS, G.R. 1965. Quantitative Differences in Susceptibility to Nuclear-Polyhedrosis Virus Among Larval Instars of the Forest Tent Caterpillar, Malacosoma disstria (Hübner). J. Invertebr. Pathol., New York, 7:427-429.

VALICENTE, F.H.; I. CRUZ, 1991. Controle Biológico da Lagartado-Cartucho, Spodoptera frugiperda, com o Baculovírus. Sete Lagoas: EMBRAPA-CNPMS. 23p. (EMBRAPA-CNPMS. Circular Técnica, 15).

WILLIAMS, C.F.; C.C. PAYNE, 1984. The Susceptibility of Heliothis armigera Larvae to Three Nuclear Polyhedrosis Viruses. Ann. Appl. Biol., Cambridge, 104: 405-412. 